\title{
Optimizing Bob Guthrie's legacy-Storage and use of residual newborn screening specimens
}

\author{
Dianne Webster, PhD
}

$S_{\mathrm{d} o w}^{\mathrm{c}}$ creening of newborn babies for congenital metabolic disorders is done in most countries worldwide. The great majority of testing is done using capillary blood collected onto absorbent paper and dried, as introduced by the late Professor Bob Guthrie. Since screening started in the 1960 s, it has been the practice of programs to retain test cards after the completion of analysis and result reporting, to allow retrospective analysis of samples collected from infants who subsequently presented with a screened disorder. This investigation of false-negative screens is an essential part of public health screening and has been possible in this case by the stability of analytes and the ease of storage of blood dried on paper. Storage of these samples was begun in good faith by screeners in the healthcare climate of the 1960 s in most cases without any policy for term of storage, potential uses, or permission for access. The development of molecular genetics technology (in healthcare and forensics) in the 1980s brought increased use of residual cards for purposes other than newborn screening, such as investigation of genetic disorders in families (e.g., determination of the mutation status of a deceased child known to be affected with such a disorder to allow prenatal diagnosis in a subsequent pregnancy). Law enforcement agencies were also making use of the technology to identify criminals and developing "DNA databases" for the purpose which is separate from newborn screening. Publicity around the forensic use of residual material has led to international concern about the possible uses of this material and compromise of individual privacy.

In the United States, the Secretary of Health and Human Services' Advisory Committee on Heritable Disorders in Newborns and Children has addressed this concern by the development of a report with recommendations for further action. This report has been reviewed by a distinguished team and their reflections published in the article by Therrell et al. ${ }^{1}$ in this issue of the journal.

The recommendations are not contentious or surprising that programs have policies in this area (including disposition of samples after the completion of screening) and that consideration be given to a national policy; that healthcare professionals and families receive education in this area and that consent issues be explored (taking local conventions into account when considering consent for research). Although the report was written for the US context, the principles have international applicability and should be considered by all programs which store samples.

The emphasis throughout the discussion on the importance of maintenance of public confidence in the screening program is

From the LabPlus, Auckland City Hospital, Auckland, New Zealand.

Dianne R. Webster, PhD, LabPlus, Auckland City Hospital, Auckland, New Zealand. E-mail: diannew@adhb.govt.nz.

Disclosure: The author declares no conflict of interest

Published online ahead of print June 15, 2011

DOI: $10.1097 /$ GIM.0b013e3182233fe6 well placed. Use of residual samples must not be allowed to jeopardize participation of newborns in screening.

In Australasia, practices also vary. Storage is between 2 years and indefinite. Information about storage is on all parent information sheets; some Australian programs allow parent access after 2 years either for return of samples to the family or to request destruction. All Australasian parent information sheets mention the possibility of research use of deidentified samples, some give additional information about alternative uses including forensic. A regional policy about storage and use of residual material has been developed by the Joint Newborn Screening Subcommittee of the Human Genetics Society of Australasia and the Royal Australasian College of Physicians Division of Pediatrics. $^{2}$

In New Zealand, the cards have been stored since introduction of the program in 1969 , to investigate false-negative results, and cards have been used for this purpose consistent with our continuous quality improvement culture. Deidentified cards are also used for method improvement and assay control within the laboratory. Cards continue to be stored indefinitely awaiting a Government decision following public consultation.

The New Zealand program is bound under the Health and Disability Commissioner Code of Health and Disability Consumers Rights Regulation $1996^{3}$ to return samples to families on request (this regulation also covers research uses of residual material), and this is done immediately after testing is complete (or later if the request is made later). Approximately $1 \%$ of cards are returned to families. New Zealand Māori have a strong sense that the body is tapu (sacred or special), and this extends to respect for removed body parts including blood. The request for return of a newborn screening card may, therefore, be made, so that it can be stored or disposed of in a culturally acceptable way. Other requests may be because of confusion between stored cards and Police DNA databases. Some programs in the region offer destruction of the card as an alternative to return to family.

After returns to families, the next most common use of residual samples is for family health reasons. They have been commonly used to assess the possibility of inborn errors of metabolism in symptomatic infants before the introduction of expanded newborn screening; to establish whether cytomegalovirus infection was congenital in children with deafness thought to be due to this infection and to identify long qt syndrome in sudden death. In this case, cards up to 39 years old have been used up to 13 years after death. ${ }^{4}$ Clinicians will appreciate the value of information about the cause of disability or death to families, both to answer the universal "why?" and to inform healthcare for other family members. This aspect of the value of stored cards may have been underestimated in the discussion by Therrell et al. ${ }^{1}$ and should be included in both family and professional education.

A minor use of stored cards is identification of body parts. A Memorandum of Understanding between the Ministry of Health and Police formalizes the process for requesting forensic use of residual material and includes the requirement that all other possible sources of identification have been exhausted and that 
family consent be obtained. ${ }^{5}$ This process could be used to provide material to allow the identification of human remains following natural disasters, large-scale accidents, e.g., airline crashes and discovered remains. There have been very few uses of cards for this purpose in Australasia all in cases where the person from whom the blood was collected is dead or missing.

Residual samples can only be used to identify individuals if they are analyzed and digitized or if the name of the individual is known. They are of limited use in criminal contexts as there is no provenance and sample mislabeling is a well-known phenomenon. Programs with stored samples must ensure forensic use is limited to uses which will be of benefit to the individual and family, with appropriate consent, regulation, and control.

An additional use is for research studies, in particular epidemiological studies. The newborn screening population is as close to a complete clean population sample as it is possible to get and information from such studies potentially very valuable, especially for conditions which may cause early death. Research approved by an Ethics Committee is allowed under the New Zealand Health and Disability Commissioner Code. ${ }^{3}$

In summary, the stored cards may stored or returned to the family. If residual material is stored, it may be used for program quality improvement; family health investigations; or identification of body parts. It is critical that these uses do not jeopardize public confidence and participation in newborn metabolic screening. In our region, there has been considerable benefit from uses of stored cards and very little (if any) harm. Program leaders worldwide should consider the recommendations of the Committee ${ }^{1}$ in their own cultural and legislative contexts taking whatever action is required to maximize all the benefits of Bob Guthrie's legacy.

\section{ACKNOWLEDGMENTS}

The author thanks Kathy Bendikson, Bridget Wilcken, and Barry Lewis for review and helpful suggestions.

\section{REFERENCES}

1. Therell BL Hannon WH, Bailey DB, et al. Committee report: considerations and recommendations for national guidance regarding the retention and use of residual dried blood spot specimens after newborn screening. Genet Med 2011;13:621-624.

2. HGSA. Retention storage and use of sample cards from newborn screening programs. Available at: https://www.hgsa.org.au/website/wp-content/uploads/ 2009/12/2000-P03.pdf. Accessed May 5, 2011

3. HDC. Health and Disability Commissioner Act 1994 No 88 (as at 03 March 2010), Public Act and the Code of Rights. Available at: http://www.hdc.org.nz/ the-act-code/the-code-of-rights. Accessed May 5, 2011.

4. Gladding P, Evans C, Crawford J, et al. Posthumous diagnosis of long QT syndrome from neonatal screening cards. Heart Rhythm 2010;7:481-486.

5. MOH. Memorandum of understanding between the Ministry of Health and the New Zealand Police relating to the disclosure of newborn blood spot cards and related information. Available at: http:/www.nsu.govt.nz/publications/ 1454.asp. Accessed February 5, 2011. 